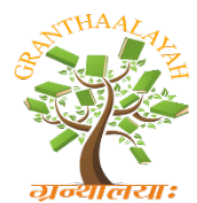

\author{
INTERNATIONAL JOURNAL OF RESEARCH - \\ GRANTHAALAYAH \\ A knowledge Repository
}

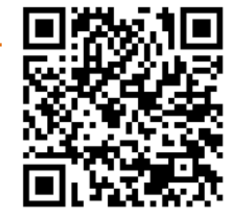

Science

\title{
QUALITY OF HOSPITAL CARE IN THE DELIVERY AND POSTPARTUM AREA OF TEOFIL DÁVILA GENERAL HOSPITAL
}

\author{
Obsta. Vicky Narea Morales MSc ${ }^{1}$, Dr. Jorge Daher Nader PHd ${ }^{2}$, Obsta Katherine \\ Rodríguez ${ }^{1}$, Obsta Gabriel Jimenez ${ }^{1}$, Obsta. Cynthia Carolina Armijo Baño ${ }^{1}$ \\ ${ }^{1}$ Teachers of The Career of Obstetrics of The Faculty of Medical Sciences of The University of \\ Guayaquil-Ecuador
}

\begin{abstract}
The quality of care in hospital services indicates that it is a matter of academic debate as there are various approaches to its measurement, control and monitoring. The objective is to evaluate the quality of hospital care, analyzing the satisfaction of mothers during the prepartum, delivery and postpartum period at the Teófilo Dávila General Hospital in Machala. The sample was of 200 patients from the area of Gynecology - Obstetrics. The study covers the period between March August 2019. The research is descriptive, not experimental, it was cross-sectional, since the data were taken only once; the investigation technique was the survey and observation, the instrument that was used was the questionnaire. As a result, it is evident that $95 \%$ of the respondents give a $9 / 10$ rating to the quality of care during delivery, $83 \%$ give a rating of 9 during the delivery care. And it is shown that the satisfaction of the patients who were attended and surveyed was $80 \%$, understood to be satisfied during the delivery stage and $76 \%$ during the postpartum period. In conclusion, the Gyneco-Obstetrics service of Teófilo Dávila - Machala General Hospital was globally evaluated as a good quality service. The majority of patients perceive the care received as satisfactory, the study constitutes the quality of care provided by the obstetric center, taking into account each of the preparatory, childbirth and postpartum stages.
\end{abstract}

Keywords: Quality; Care; Hospital; Pre-Delivery; Delivery.

Cite This Article: Obsta. Vicky Narea Morales MSc, Dr. Jorge Daher Nader PHd, Obsta Katherine Rodríguez, Obsta Gabriel Jimenez, and Obsta Cynthia Armijos Bath. (2020). "QUALITY OF HOSPITAL CARE IN THE DELIVERY AND POSTPARTUM AREA OF TEOFIL DÁVILA GENERAL HOSPITAL." International Journal of Research - Granthaalayah, 8(3), 43-48. https://doi.org/10.5281/zenodo.3732964.

\section{Introduction}

Today there is a lot of talk about quality, since all consumers want health products and services, there is also talk of certifications and accreditations as a way to guarantee quality. Although currently one of the main issues such as the concept of quality is not new and has been a permanent concern since ancient times. The International Organization for Standardization ISO, in standard 
9001: 2015, indicates that quality is "Quality: degree to which a set of characteristics inherent in an object (product, service, process, person, organization, system or resource) complies with the requirements." In the dictionary of the Spanish Language of 1984, it defines quality as a "quality", a "way of being", "someone whose thing of general esteem" or "the best in its kind". In medicine and education, as in other fields of knowledge, the term applies to the excellence of a discipline, to the perfection of a process, to obtain good results with a certain procedure. Which means that even within this particular area, there is no single definition or characteristic for quality. The quality of service at the health level is a matter of concern due to the service that different patients, both young and old, perceive in health care facilities, this situation is the reason why an investigation has to be carried out on the level of care which is provided to people in different countries worldwide. The definition of quality in health care brings together additional aspects to the technical quality of diagnostic and therapeutic procedures, gathering skills in the way of answering questions to patients quickly and understandably, or encouraging medical procedures in such a way that do not scare patients when they receive the news about their current health status. For this reason, the issue of quality of service at the health level has been becoming important at the level of the different health institutions, both locally and internationally. In Ecuador, one of the guiding principles of sectoral policy is the quality of health care, considering it as a mandatory right that every citizen who has to have resides in the Ecuadorian territory, reference is made as the central axis of attention, user satisfaction.

However, at present, user satisfaction is used as a bridge to perform evaluations through interventions where doctors and health services take part, since this evaluation provides information about the quality perceived by clients as a structure, processes and results obtained.

The health professional plays an important role in the care aimed at women in the stage of delivery, delivery and especially in the postpartum period, which contributes to reducing maternal morbidity and mortality. This research will contribute to generating new data on the application of health care standards in the puerperal stage, which would benefit women to avoid future complications; The health professional through the data generated may take improvement or correction measures in the Gynecology-Obstetrics service.

The general objective of this research is to evaluate the quality of hospital care of pregnant women during pre-pregnancy, childbirth and puerperium at the Teófilo Dávila de Machala-Ecuador General Hospital, in the period of March - August 2019

That is why, before this problem, the following question was asked:

Are the standards of care during pre-natal, childbirth, and the immediate and medium-term puerperium applied by professional health personnel in hospitalized users in the GynecologyObstetrics service of Teófilo Dávila Canton Machala General Hospital?

What is the impact on the quality of care provided in the pre-delivery, delivery and postpartum areas of Teófilo Dávila - Machala General Hospital?

\section{Materials and Methods}

This research work corresponds to a study of quantitative approach, of a non-experimental descriptive nature, cross-sectional and analytical - descriptive type. The study covers the period 
from March 1 to August 31, 2019. The method of this investigation was deductive and its approach was quantitative. The research techniques that were used were the survey - observation. The instrument that was used was the questionnaire.

The sample of admitted patients was 200 patients, being a simple random sampling. Formula was not used since the population is less than 500 patients.

In the inclusion criteria, all patients who were treated in the preparatory stages, in the Obstetrics area of Teófilo Dávila General Hospital in the city of Machala, are included. Postpartum patients who underwent eutocic and surgical delivery, who agreed to participate in the survey. In the Exclusion criteria, all patients who do not accept to participate in the survey and do not meet the inclusion criteria will be excluded. RESULTS: To evaluate the quality of hospital care, analyzing the satisfaction of mothers during labor and postpartum

Graph \# 1 Quality of hospital care.

\begin{tabular}{|l|l|l|}
\hline Categories & Frequency & Percentage \\
\hline Satisfactory & 184 & $92 \%$ \\
\hline unsatisfactory & 15 & $7 \%$ \\
\hline nothing satisfactory & 1 & $1 \%$ \\
\hline TOTAL & 200 & $100 \%$ \\
\hline
\end{tabular}

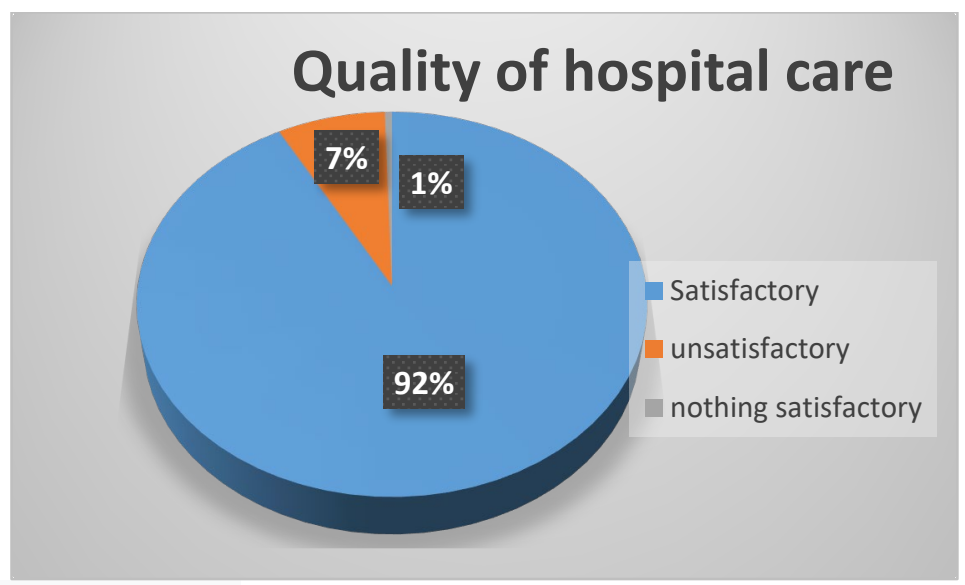

Source: Teófilo Davila - Machala

Interpretation: The qualification provided by the patient surveys with respect to the quality of hospital care, $92 \%$ satisfied, $7 \%$ unsatisfactory and $1 \%$ unsatisfactory, based on the experience they had during the delivery, delivery and puerperium. - Determine the quality of care in the postpartum area of the Teófilo Dávila General Hospital - Machala.

Graphic \# 2 Postpartum

\begin{tabular}{|l|l|l|}
\hline Categoríes & Frequency & Percentage \\
\hline Satisfactory & 170 & $85 \%$ \\
\hline unsatisfactory & 26 & $13 \%$ \\
\hline nothing satisfactory & 4 & $2 \%$ \\
\hline Total & 200 & $100 \%$ \\
\hline
\end{tabular}




\section{Quality of pospartum care}

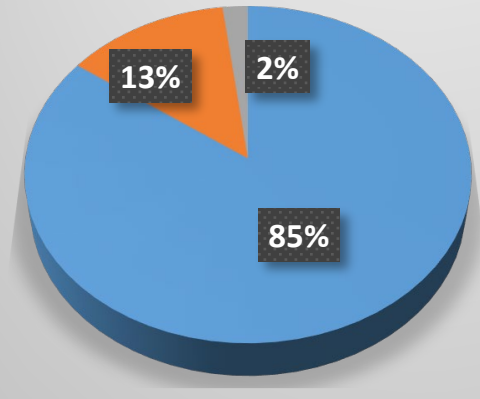

$$
\begin{aligned}
& \text { Satisfactory } \\
& \text { unsatisfactory } \\
& \text { nothing satisfactory }
\end{aligned}
$$

Source: Teófilo Dávila - Machala Hospital.

Interpretation: Meanwhile the qualification provided by the patient surveys in the postpartum area was $85 \%$ satisfactory, unsatisfactory with $13 \%, 2 \%$ unsatisfactory, indicating that the area as such should have several changes to improve the environment. Identify the level of satisfaction of the patients who are attended by health professionals during childbirth.

Graph \# 3 Quality of care in the birth area.

\begin{tabular}{|l|l|l|}
\hline Categoríes & Frequency & Percentage \\
\hline Satisfactory & 180 & $90 \%$ \\
\hline unsatisfactory & 18 & $9 \%$ \\
\hline nothing satisfactory & 2 & $1 \%$ \\
\hline TOTAL & 200 & $100 \%$ \\
\hline
\end{tabular}

\section{Quality of care in the birth area.}

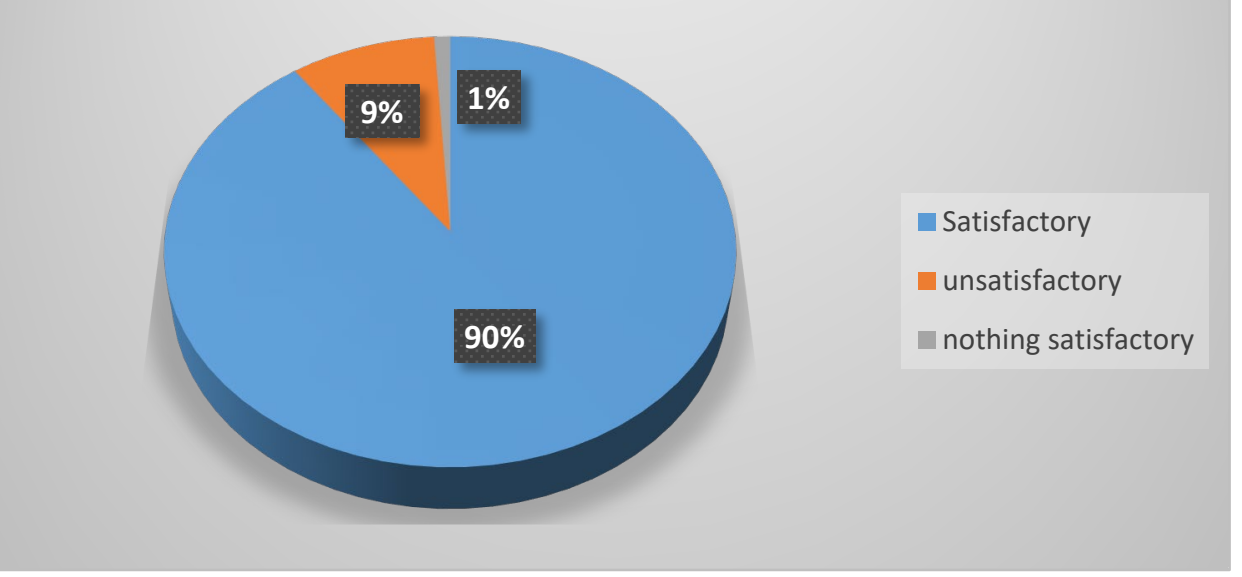

Source: Teófilo Dávila Hospital - Machala.

Interpretation: The rating provided by the patients in the delivery area for the survey was $90 \%$ satisfactory, unsatisfactory with $9 \%$, not satisfactory $1 \%$. 


\section{Conclusions}

- The OB / GYN service at the Teófilo Dávila de Machala General Hospital was globally evaluated as a good quality service. The majority of patients perceive the care received as satisfactory.

- The study constitutes a quality of service provided by the obstetric center, taking into account each stage of childbirth and the puerperium.

- The own experience lived by patients who have had previous deliveries, negatively influenced the perception of quality of care, since the study showed that multiparous and large multiparous patients showed dissatisfaction with respect to whether they were left alone for long periods of time, the doctor's communication with them and their families and respect for their privacy.

\section{Recommendations}

- It is necessary to educate women from early stages on their sexual and reproductive rights, so that they guarantee their fulfillment.

- It is necessary to carry out more research using the survey in obstetric centers in our country, which allow us to know the ideal that patients have in childbirth care and tie it with reality, also give voice to acts of violence that have been naturalized and invisibilities for a long time.

- It is important the permanent regulation of compliance with the regulations established by the Ministries of Public Health in all those health centers and hospitals that have obstetric centers, so that the indicated protocols are applied in a responsible manner in the care of childbirth in patients

\section{References}

[1] National Constituent Assembly of Ecuador. (October 20, 2008). Costitucion of the Republic of Ecuador. Retrieved from http://pdba.georgetown.edu/Parties/Ecuador/Leyes/constitucion.pdf

[2] National Assembly of the Bolivarian Republic of V. (2006). Organic Law on the Right of Women to a Life Free of Violence. Obtained from the Organic Law on the Right of Women to a Life Free of Violence.

[3] National Assembly of Ecuador. (2017). Law 67: Organic Health Law. In A. N. Ecuador, Law 67: Organic Health Law. Ecuador

[4] Avedis Donabendian. (2008). Healthcare Quality Indicators. In A. Donabendian, Indicators of quality in the critically ill (p. 7). Spain: AVEDIS DONABEDIAN FOUNDATION (FAD).

[5] Avedis Donabendian. (2008). Healthcare Quality Indicators. In A. Donabendian, Quality indicators in the critically ill patient (p. 7). Spain: AVEDIS DONABEDIAN FOUNDATION (FAD).

[6] BioMed Central. (2014). Obtained from the Clinical Way: http://viaclinica.com/article.php?pmc_id=1634747

[7] Blumenthal D. Quality of health care. (2017). The origins of the quality of care of debate. USA: Macat Library.

[8] Burneo C. Gabriela. (2017). http://dspace.unl.edu.ec. Retrieved from http://dspace.unl.edu.ec:9001/jspui/bitstream/123456789/18871/1/ATENCI\%C3\%93N\%20DE\% 20ENFERMER\%C3\%8DA\%20DURANTE\%20EL\%20PUERPERIO\%2C\%20EN\% 20EL\% 
20HOSPITAL\% 20TE\% C3\% 93FILO\% 20D\% C3\% 81VILA\% 20DE\% 20MACHALA\% 2C\% 202017.pdf Carrillo, RG (sf). Satisfaction with the quality of care in women. CONAMED

[9] National Directorate of Standardization - MSP. (2015). Clinical Practice Guide (GPC). Ecuador: National Standardization Directorate - MSP;

[10] Florence Gillet-Goinard. (2014). QA. Mexico: Editorial Patria.

[11] Germán Pineda, \& Cristina Seijo. (2012). Leadership and Service Quality. Mexico: EAE.

[12] INEC. (2013). National Institute of Statistics and Census. Obtained from Yearbook Births and Deaths 2013: http://www.eficienterencifras.gob.ec/documentos/webinec/Poblacion_y_Demografia/Nacimiento_Defunciones/Publicaciones/Anuario_Nacimiento_y_ Defunciones_2013.pdf.

[13] WHO. (2016). World Health Organization. Retrieved from https://apps.who.int/iris/bitstream/handle/10665/272435/WHO-RHR-18.12-spa.pdf

[14] World Health Organization. (June 06, 2017). https://www.who.int. Obtained from health care alidad: https://www.who.int/bulletin/volumes/95/6/16-180190-ab/es/

* Corresponding author.

E-mail address: Vicky.naream@ug.edu.ec/Jorge.dahern@ug.edu.ec/Katherine.rodriguezb@ug.edu.ec/ Gabriel jimenezV@ug.edu.ec/CynthiaB@hotmail.com 